PPPL-3179, Preprint: May 1996, UC-420, 426

Search for Alpha-Driven BAE Modes in TFTR

W.W. Heidbrink, et al.

A search for alpha-driven beta-induced Alfvén eigenmodes (BAE modes) was conducted in low current (1.0-1.6 MA) TFTR supershots. Stable high-beta deuterium-tritium (DT) discharges were obtained with $\mathrm{B} \rho=2.4$ and central alpha beta of $0.1 \%$. Instabilities beween 75$200 \mathrm{kHz}$ were observed by magnetic probes in many DT discharges, but the activity was also present in deuterium-deuterium (DD) comparison discharges, indicating that these modes are not destabilized (principally) by the alpha-particle population. Losses of fusion products are also similar in the two sets of discharges.

\title{
DISCLAIMER
}

This report was prepared as an account of work sponsored by an agency of the United States Government. Neither the United States Government nor any agency thereof, nor any of their employees, makes any warranty, express or implied, or assumes any legal liability or responsibility for the accuracy, completeness, or usefulness of any information, apparatus, product, or process disclosed, or represents that its use would not infringe privately owned rights. Referprocess disclosed, or represents that its use would not infringe privately owned rights. Refermanufacturer, or otherwise does not necessarily constitute or imply its endorsement, recommendation, or favoring by the United States Government or any agency thereof. The views and opinions of authors expressed herein do not necessarily state or reflect those of the United States Government or any agency thereof. 


\section{Search for Alpha-Driven BAE Modes in TFTR}

W.W. Heidbrink, ${ }^{1}$ S. Batha, ${ }^{2}$ R. Bell, ${ }^{3}$ Z. Chang, ${ }^{3}$ D. Darrow, ${ }^{3}$ J. Fang, ${ }^{1}$ E. Fredrickson, ${ }^{3}$ R.A. James,${ }^{4}$ F. Levinton, ${ }^{2}$ R. Nazikian, ${ }^{3}$ S. Paul, ${ }^{3}$ E. Ruskov, ${ }^{1}$ S. Sabbagh, ${ }^{5}$ E.J. Strait, ${ }^{6}$ E. Synakowski, ${ }^{3}$ G. Taylor, ${ }^{3}$ A.

Turnbull, ${ }^{6}$ K.-L. Wong, ${ }^{3}$ and S. Zweben ${ }^{3}$

${ }^{1}$ University of California. Irvine. California, USA

${ }^{2}$ Fusion Physics and Technology, Torrance, California, USA

${ }^{3}$ Princeton Plasma Physics Laboratory, Princeton, New Jersey, USA

${ }^{4}$ Lawrence Livermore National Laboratory, Livermore, California. USA

${ }^{5}$ C'olumbia University, New York, New York, USA

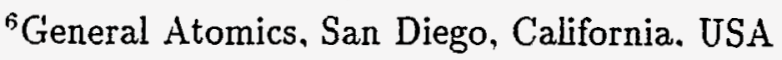

ABSTRACT. A search for alpha-driven beta-induced Alfvén eigenmodes (BAE modes) was conducted in low current (1.0-1.6 MA) TFTR supershots. Stable high-beta deuterium-tritium (DT) discharges were obtained with $\beta_{p}=2.4$ and central alpha beta of $0.1 \%$. Instabilities between 75 $200 \mathrm{kHz}$ were observed by magnetic probes in many DT discharges. but the activity was also present in deuterium-deuterium (DD) comparison discharges. indicating that these modes are not destabilized (principally) by the alpha-particle population. Losses of fusion products are also similar in the two sets of discharges.

To be submitted as a Nuclear Fision Letter. 
bers of deuterium and tritium neutral sources were injected into nineteen "DT" discharges; an additional 140 "DD" discharges with deuterium injection alone comprise the remainder of the dataset. The operational strategy had four steps.

1. Steadily increase the number of beam sources $N_{S}$ in DD plasmas until a disruption occurs; time the sources so the disruption occurs approximately $1.0 \mathrm{~s}$ after the start of beam injection. (Pushing the plasma to the disruptive limit maximizes $\beta_{p}$, while delaying the disruption for an alpha-particle slowing-down time yields a maximal value of $\beta_{\alpha}$ in subsequent DT shots.)

2. After reconditioning the walls, produce approximately ten DD discharges with $N_{S}-1$ sources to reestablish reproducibility.

3. Convert half of the neutral beams to tritium and produce a DT discharge with $N_{S}$ sources.

4. Produce a DD comparison discharge with $N_{S}$ or $N_{S}+1$ sources.

The beam power varied from $5-22 \mathrm{MW}$, the beam voltage was typically $100 \mathrm{keV}$. and a similar neutral beam power was injected both parallel and anti-parallel to the plasma current ("balanced" injection). Plasmas with toroidal fields $B_{T}$ of $3.3,4.7$. and $5.1 \mathrm{~T}$ and currents $I_{p}$ between 0.7 and 1.6 MA were produced.

Relative to other TFTR DT discharges, the distinctive feature of these experiments is the use of a low, steady plasma current. Figure 1 compares the best 1.0 MA discharge with a 2.5 MA discharge that had a large value of $\beta_{\Omega}$ [11]. Since the maximum pressure in TFTR supershots is governed by a central beta limit that scales with the normalized current $I_{p} / a B_{T}$. the maximum beam power in our low-current discharges is about half as large as in high-current supershots (Fig. 1). The stored energy $W$ is also $\sim 50 \%$ smaller. so the fusion reaction rate is only about $1 / 3$ of the high-current value. Since disruptions were delayed until the alpha pressure had peaked. the resulting central alpha beta is also about $1 / 3$ of the high-current value (Fig. 1). On the other hand. the low-current discharge has a relatively large beta limit for TFTR (product of normalized beta and density peaking factor $3_{v} n_{e}(0) /\left\langle n_{e}\right\rangle=6.8$ ), so the poloidal beta is $\sim 3$ times larger than in high-current supershots (Fig. 1).

As is typical for supershots. the spatial profiles peak strongly at the magnetic axis (Fig. 2). The density is relatively low and the beam fuelling 
value of the magnetics signal does not necessarily coincide with the maximum value of the alpha density.

- Scintillators at three different poloidal locations $\left(45^{\circ}, 60^{\circ}\right.$, and $\left.90^{\circ}\right)$ measure fusion-product losses. The temporal evolution of the signals is very similar in DT and DD discharges. The signals appear consistent with the expected evolution associated with prompt losses [26]. Little or no correlation with the magnetic fluctuations is observed. If anomalous losses occur, they are much smaller ( $\$ 10 \%)$ than the prompt losses.

- For a representative subset of the DT and DD discharges, coherent core fluctuations are not observed between 50 and $150 \mathrm{kHz}$ by the reflectometer diagnostic [27]. Signals from the electron cyclotron emission grating polychromator [14] are similar in DT and DD discharges.

- For discharge \#85863. the beam-emission spectroscopy diagnostic [28] does not observe any coherent fluctuations above $60 \mathrm{kHz}$.

This qualitative assessment is supported by a quantitative analysis of the magnetics and scintillator data. Measurements at 2-3 different times for every discharge in the dataset were entered into a database. If $\mathrm{BAE}$ modes were destablized by alpha particles, the mode amplitude at large $\beta_{p}$ should be larger in DT shots than in DD shots, but this is not observed for fluctuations between $100-150 \mathrm{kHz}$ (Fig. 6). Similar results are obtained in the $75-9.5 \mathrm{kHz}$ frequency band. The mode amplitude also does not correlate with the $14 \mathrm{MeV}$ neutron emission (the alpha creation rate) $S_{D T}$ or with other plasma parameters $\left(I_{p}, \bar{n}_{e}, B_{T}, W, \tau_{E}, P_{B}\right)$.

Similar results are obtained for the scintillator data. For all three detectors. the normalized signal (loss/neutron) depends weakly on the magnetics amplitude and on $; \beta_{p}, S_{D T} . I_{p}, \bar{n}_{e} . n_{e}(0) /\left\langle n_{e}\right\rangle, B_{T}, W, \tau_{E}$, and $P_{B}$.

In retrospect, the null result of this experiment is not surprising.

- In DIII-D, the stability threshold for the beam-driven BAE mode is comparable to the stability threshold for the beam-driven TAE mode [2]. So far, TAE modes driven by alpha particles alone have not been observed in TFTR [29-31] (even in plasmas with $\sim 3$ times larger alpha pressure than in our discharges). In one experiment [32]. the minority ions created by ion cyclotron heating supplemented the instability drive produced by the alpha particles. In this experiment. 


\section{References}

[1] HEIDBRINK, W. W., STRAIT, E. J., DOYLE, E., SAGER, G., and SNIDER, R. T., Nucl. Fusion 31 (1991) 1635.

[2] HEIDBRINK, W. W., STRAIT, E. J., CHU, M. S., and TURNBULL, M. S., Phys. Rev. Lett. 71 (1993) 855.

[3] CHU, M. S., GREENE, J. M., LAO, L. L., TURNBULL, A. D., and CHANCE, M. S., Phys. Fluids B 4 (1992) 3713.

[4] HEIDBRINK, W. W., CAROLIPIO, E. M., JAMES, R. A., and STRAIT, E. J., Nucl. Fusion 35 (1995) 1481.

[5] NAZIKIAN, R., CHANG, Z., FREDRICKSON, E. D., et al., Phys. Plasma 3 (1996) 593.

[6] TSAI, S.-T. and CHEN, L., Phys. Fluids B 5 (1993) 3284.

[7] BRIGUGLIO, S., KAR, C., ROMANELLI, F., VLAD, G., and ZONCA, F., Plasma Phys. Controlled Fusion 37 (1995) A279.

[8] CHENG. C. Z., GORELENKOV, N. N., and HSU, C. T., Nucl. Fusion 35 (199.5) 1639.

[9] SANTORO, R. A. and CHEN, L.. Phys. Plasma 3 (1996) in press.

[10] STRACHAN, J. D.. Nucl. Fusion 34 (1994) 1017.

[11] BUDNY, R. V.. BELL. M. G.. JANOS, A. C., et al., Nucl. Fusion 35 (1995) 1497.

[12] BUDNY, R. V., Nucl. Fusion 34 (1994) 124 i.

[13] PARK, H. K., Rev. Sci. Instrum. 61 (1990) 2879.

[14] JANOS, A., MCCARTHY. M.. FREDRICKSON. E., MCGUIRE. K.. and TAYLOR, G.. Rev. Sci. Instrum. 66 (1995) 668.

[15] STAUFFER. F. J., BOYD. D. A.. CUTLER, R. C., et al., Rev. Sci. Instrum. 56 (198.5) 925.

[16] SYNAKOWSKI, E. J.. BELL. R. E.. and BUSH, C. E., Rer. Sci. Instrum. 66 (1995) 649. 
[33] Chang, Z., BUdNy, R. V., CHEN, L., et al., Phys. Rev. Lett. 76 (1996) 1071. 
numbers inferred [20] from the relative phase of the probe data are given.

Figure 5. Time evolution of $\beta_{p}$, bandpass-filtered magnetics signal. and the normalized fusion product losses in the DT shot \#85863 and in a comparison DD discharge (\#85864). The fusion-product detector [25] measures alpha particles in the DT discharge (the signal is normalized to the DT neutron emission). In the DD discharge, alpha particles produce $\sim 65 \%$ of the signal and tritons and protons produce the remaining $\sim 35 \%$. (Since the DD fusion products produce $2 / 3$ of the light produced by alpha particles [25], the signal is normalized to $S_{D T}+\frac{2}{3} S_{D D}$.) The detector is at the bottom of the machine $\left(90^{\circ}\right)$.

Figure 6. Bandpass magnetics amplitude versus $\beta_{p}$ for DT (circle) and DD (square) discharges. 

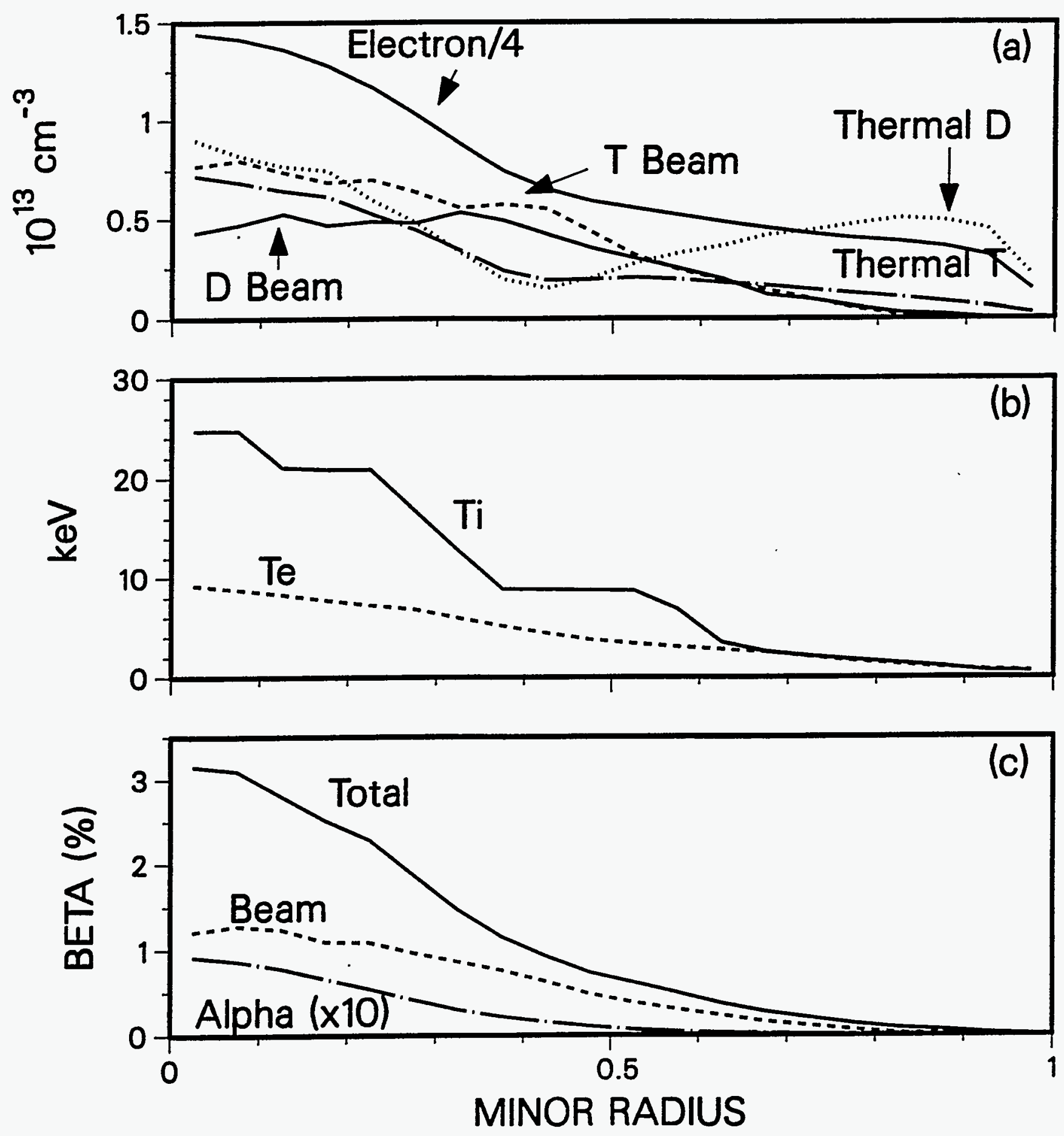

Fig. 2 


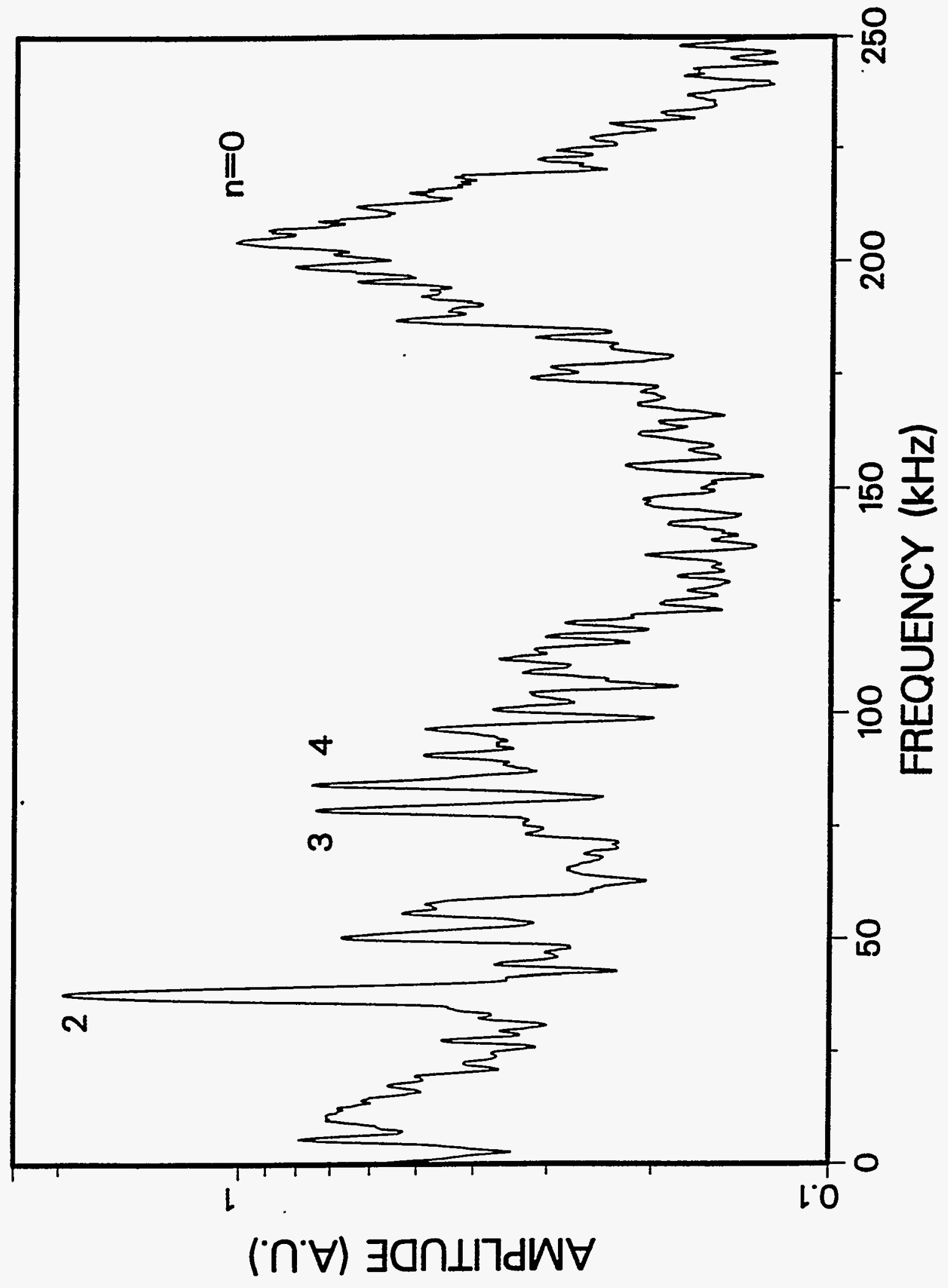

Fig. 4 


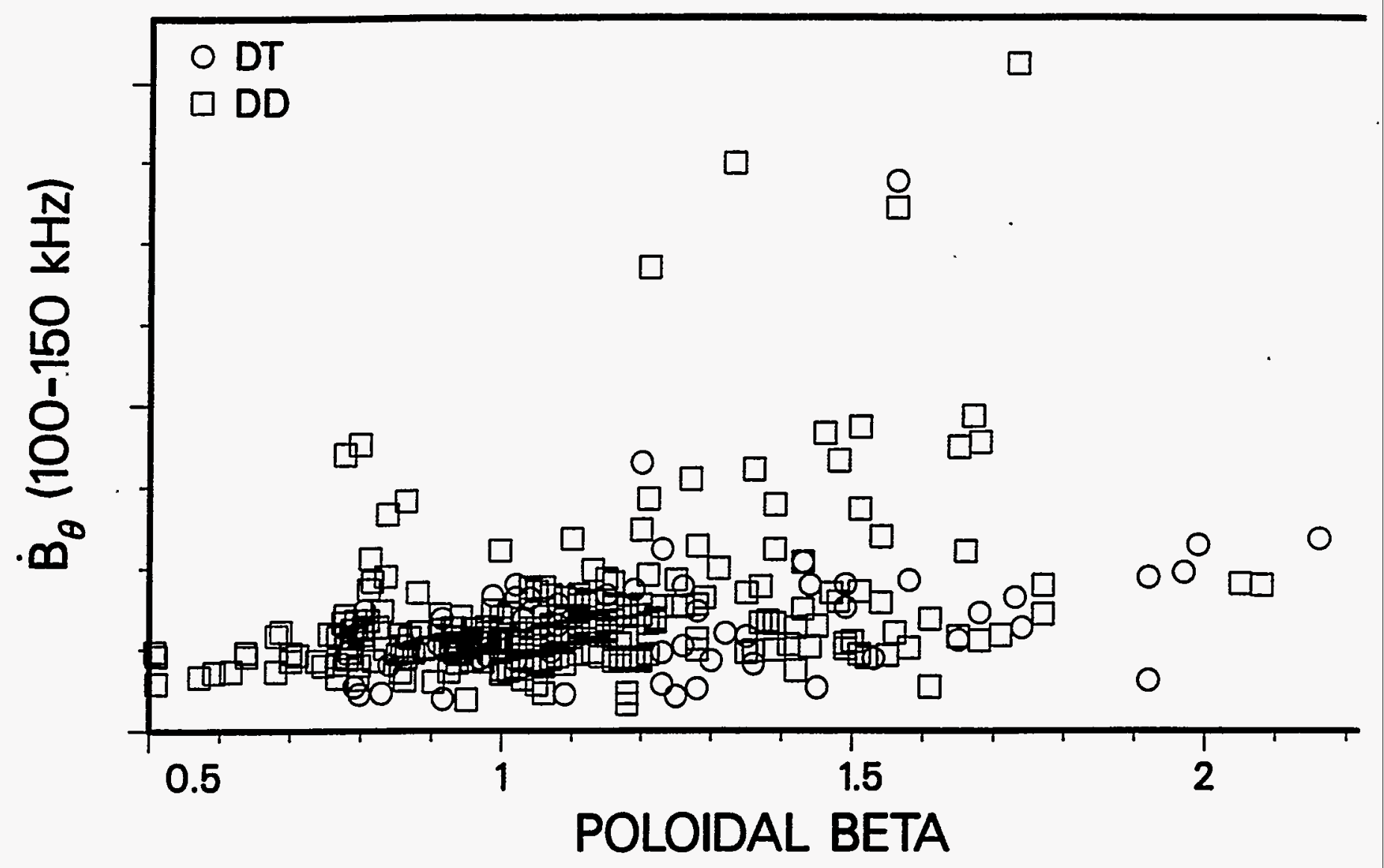

Fig. 6 


\title{
PPPL-3179, Preprint: May 1996, UC-420, 426
}

\section{Search for Alpha-Driven BAE Modes in TFTR}

\author{
W.W. Heidbrink, et al.
}

A search for alpha-driven beta-induced Alfvén eigenmodes (BAE modes) was conducted in low current (1.0-1.6 MA) TFTR supershots. Stable high-beta deuterium-tritium (DT) discharges were obtained with $\mathrm{B} \rho=2.4$ and central alpha beta of $0.1 \%$. Instabilities beween 75 $200 \mathrm{kHz}$ were observed by magnetic probes in many DT discharges, but the activity was also present in deuterium-deuterium (DD) comparison discharges, indicating that these modes are not destabilized (principally) by the alpha-particle population. Losses of fusion products are also similar in the two sets of discharges.

\section{DISCLAIMER}

This report was prepared as an account of work sponsored by an agency of the United States Government. Neither the United States Government nor any agency thereof, nor any of their employees, makes any warranty, express or implied, or assumes any legal liability or responsibility for the accuracy, completeness, or usefulness of any information, apparatus, product, or bility for the accuracy, completeness, or usefulness of any infor infinge privately owned rights. Reference herein to any specific commercial product, process, or service by trade name, trademark, manufacturer, or otherwise does not necessarily constitute or imply its endorsement, recommendation, or favoring by the United States Government or any agency thereof. The views and opinions of authors expressed herein do not necessarily state or reflect those of the United States Government or any agency thereof. 
.

. 


\section{Search for Alpha-Driven BAE Modes in TFTR}

W.W. Heidbrink, ${ }^{1}$ S. Batha, ${ }^{2}$ R. Bell, ${ }^{3}$ Z. Chang, ${ }^{3}$ D. Darrow, ${ }^{3}$ J. Fang, ${ }^{1}$ E. Fredrickson, ${ }^{3}$ R.A. James, ${ }^{4}$ F. Levinton, ${ }^{2}$ R. Nazikian, ${ }^{3}$ S. Paul, ${ }^{3}$ E. Ruskov, ${ }^{1}$ S. Sabbagh, ${ }^{5}$ E.J. Strait, ${ }^{6}$ E. Synakowski, ${ }^{3}$ G. Taylor, ${ }^{3}$ A. Turnbull, ${ }^{6}$ K.-L. Wong, ${ }^{3}$ and S. Zweben ${ }^{3}$

${ }^{1}$ University of California. Irvine, California, USA

'Fusion Physics and Technology, Torrance, California, USA

${ }^{3}$ Princeton Plasma Physics Laboratory, Princeton, New Jersey, USA

${ }^{4}$ Lawrence Livermore National Laboratory, Livermore. California, USA

${ }^{5}$ Columbia University, New York, New York, USA

${ }^{6}$ General Atomics, San Diego, California. USA

ABSTRACT. A search for alpha-driven beta-induced Alfvén eigenmodes (BAE modes) was conducted in low current (1.0-1.6 MA) TFTR supershots. Stable high-beta deuterium-tritium (DT) discharges were obtained with $\beta_{p}=2.4$ and central alpha beta of $0.1 \%$. Instabilities between 75 $200 \mathrm{kHz}$ were observed by magnetic probes in many DT discharges. but the activity was also present in deuterium-deuterium (DD) comparison discharges. indicating that these modes are not destabilized (principally) by the alpha-particle population. Losses of fusion products are also similar in the two sets of discharges.

To be submitted as a Nuclear Fusion Letter. 
Alpha particles are produced in DT fusion reactions. In a tokamak reactor, intense alpha populations might drive instabilities that cause anomalous transport of the alpha particles, resulting in degraded plasma performance or damage to internal vacuum-vessel hardware. It is important, therefore, to determine the stability threshold of alpha-driven instabilities.

In DIII-D experiments that are designed to simulate alpha:particle effects, intense beam-ion populations destabilize two types of Alfvén instabilities, the toroidicity-induced Alfvén eigenmode (TAE) [1] and the betainduced Alfvén eigenmode ( $\mathrm{BAE}$ ) [2]. The $\mathrm{BAE}$ modes have frequencies that are $\sim 40 \%$ of the TAE frequency [2] (in a low frequency gap beneath the Alfvén continuum of ideal IIHD [3].) BAE modes occur in high-beta plasmas. They were first observed in plasmas where the fast-ion speed was comparable to the Alfvén speed. but were later seen in plasmas with subAlfvénic fast-ion populations [ 4 ].

Motivated by these simulation experiments. we tried to destabilize BAE modes with alpha particles in the Tokamak Fusion Test Reactor (TFTR). At the time of the experiment there were no theoretical predictions of BAE stability, so we adopted an empirical approach. Our operational goal was to maximize the alpha particle pressure (to maximize the instability drive) at a large value of poloidal beta (to maximize the low-frequency gap in the Alfvén continuum). No alpha-driven BAE modes were observed.

Since the time of the experiment, more has been learned about instabilities in the BAE gap. Experimental work on TFTR found that instabilities in this band have frequencies comparable to $\omega_{* p i} / 2[.: 5] .\left(\omega_{* p i}\right.$ is the ion diamagnetic frequency), as expected for kinetic ballooning modes [6]. Numerical studies [7-9] discovered energetic particle modes (modes that do not exist in the absence of a fast-ion population) with frequencies similar to the "BAE" modes observed in DIII-D. I recent unified theoretical treatment of the background plasma behavior (in the absence of energetic particles) finds that the most unstable rcgime corresponds to a coupling between the driftlike KBM branch and the .Ilfvenic B.IE branch. Comparison of these new theories with the observed instabilitips is the topic of a future paper. This letter addresses the effect of alpha particles on modes in this $B A E / K B M$ frequency band.

The data were obtained during a wepk of TFTR operation in April 1995. The plasmas were limited on a wroll-ronditioned inner wall (major radius $R=2.52 \mathrm{~m}$. minor radius $a=0.5, \mathrm{~cm})$ and the confinement was characteristic of supershots [ $[10]$ (typical $\left.i_{E} \simeq 0.16 s\right)$. Approximately equal num- 
bers of deuterium and tritium neutral sources were injected into nineteen "DT" discharges; an additional 140 "DD" discharges with deuterium injection alone comprise the remainder of the dataset. The operational strategy had four steps.

1. Steadily increase the number of beam sources $N_{S}$ in DD plasmas until a disruption occurs; time the sources so the disruption occurs approximately $1.0 \mathrm{~s}$ after the start of beam injection. (Pushing the plasmia to the disruptive limit maximizes $\beta_{p}$, while delaying the disruption for an alpha-particle slowing-down time yields a maximal value of $\beta_{\alpha}$ in subsequent DT shots.)

2. After reconditioning the walls, produce approximately ten DD discharges with $N_{S}-1$ sources to reestablish reproducibility.

3. Convert half of the neutral beams to tritium and produce a DT discharge with $N_{S}$ sources.

4. Produce a DD comparison discharge with $N_{S}$ or $N_{S}+1$ sources.

The beam power varied from $5-22 \mathrm{MW}$, the beam voltage was typically $100 \mathrm{keV}$. and a similar neutral beam power was injected both parallel and anti-parallel to the plasma current ("balanced" injection). Plasmas with toroidal fields $B_{T}$ of $3.3,4.7$, and $5.1 \mathrm{~T}$ and currents $I_{p}$ between 0.7 and 1.6 MA were produced.

Relative to other TFTR DT discharges, the distinctive feature of these experiments is the use of a low, steady plasma current. Figure 1 compares the best $1.0 \mathrm{MA}$ discharge with a $2.5 \mathrm{MA}$ discharge that had a large value of $\beta_{r}$ [11]. Since the maximum pressure in TFTR supershots is governed by a central beta limit that scales with the normalized current $I_{p} / a B_{T}$, the maximum beam power in our low-current discharges is about half as large as in high-current supershots (Fig. 1). The stored energy $W$ is also $\sim 50 \%$ smaller. so the fusion reaction rate is only about $1 / 3$ of the high-current value. Since disruptions were delayed until the alpha pressure had peaked. the resulting central alpha beta is also about $1 / 3$ of the high-current value (Fig. 1). On the other hand. the low-current discharge has a relatively large beta limit for TFTR (product of normalized beta and density peaking factor $\left.3_{v} n_{e}(0) /\left\langle n_{e}\right\rangle=6.8\right)$, so the poloidal beta is $\sim 3$ times larger than in high-current supershots (Fig. 1).

As is typical for supershots. the spatial profiles peak strongly at the magnetic axis (Fig. 2). The density is relatively low and the beam fuelling 
is strong, so the beam density is comparable to the thermal ion densities and the central beam pressure is a large fraction $(\sim 40 \%)$ of the total. The alpha pressure is an order of magnitude smaller. The large value of poloidal beta creates a relatively large low-frequency gap in the Alfvén continuum (Fig. 3).

In addition to disruptions. three types of instabilities are observed in most of these high beta plasmas (Fig. 4). In the low frequency band ( $\lesssim 50 \mathrm{kHz}$ ), modes with toroidal mode numbers $n$ between 1-4 are seen [21]. These modes are probably tearing modes [22]. At higher frequencies $(\gtrsim 200 \mathrm{kHz})$, modes with the characteristics of edge Alfvén modes [23] are observed. These modes have toroidal mode number $n=0$, extend over a relatively large range of frequencies, and do not correlate with observable fast-ion losses. It is the modes in the intermediate frequency band $(50-150 \mathrm{kHz})$ that are of greatest -interest for this study. These modes often appear as a "cluster" of several modes separated in frequency by $\sim 10 \mathrm{kHz}$. The clusters consist of $2-4$ peaks with successively increasing toroidal mode numbers between $n=2$ and 5 . Their features closely resemble the BAE modes observed in DIII-D [2]. In other cases, single modes with $n=1-j$ appear in this frequency band.

Like the DIII-D BAE modes. these intermediate-frequency modes have frequencies that fall in the low-frequency gap beneath the Alfvén continuum of ideal MHD (Fig. 3). In a frame rotating with the plasma, all of the toroidal modes in a cluster have nearly the same frequency in the interior of the plasma. (In other words. the splitting of the peak into a "cluster" is probably caused by the Doppler shift.) Calculations with the ideal MHD code GATO reveal global eigenmodes in the center of the plasma with frequencies close to the measured frequency (Fig. :3). There eigenmodes resemble the theoretical "BAE" modes computed for DIII-D expuilibria [24]. The internal frequency is also comparable to the expected frequency [6] of kinetic ballooning modes (Fig. 3).

Having established that these plaimas can support "BAE" modes similar to those observed in DIII-D. we procered to an examination of the effect of alpha particles on the modes. () n! . pproroch is to compare DT discharges with companion DD discharges i hal haim imilar plasma parameters (Fig. 5). No effect correlated specifically will . lpha particles is observed.

- A bank of bandpass filter andires the Ructuations measured by a magnetic probe. The amplimino of the fluctuations is comparable in DT and DD comparison disciarem in both the $75-95 \mathrm{kHz}$ filter band and in the 100-150 kII\% fillor baud. .1/so. in DT discharges, the peak 
value of the magnetics signal does not necessarily coincide with the maximum value of the alpha density.

- Scintillators at three different poloidal locations $\left(45^{\circ}, 60^{\circ}\right.$, and $\left.90^{\circ}\right)$ measure fusion-product losses. The temporal evolution of the signals is very similar in DT and DD discharges. The signals appear consistent with the expected evolution associated with prompt losses [26]. Little or no correlation with the magnetic fluctuations is observed. If anomalous losses occur, they are much smaller ( $\lesssim 10 \%)$ than the prompt losses.

- For a representative subset of the DT and DD discharges, coherent core fluctuations are not observed between 50 and $150 \mathrm{kHz}$ by the reflectometer diagnostic [27]. Signals from the electron cyclotron emission grating polychromator [14] are similar in DT and DD discharges.

- For discharge \#85863. the beam-emission spectroscopy diagnostic [28] does not observe any coherent fluctuations above $60 \mathrm{kHz}$.

This qualitative assessment is supported by a quantitative analysis of the magnetics and scintillator data. Measurements at 2-3 different times for every discharge in the dataset were entered into a database. If $\mathrm{BAE}$ modes were destablized by alpha particles, the mode amplitude at large $\beta_{p}$ should be larger in DT shots than in DD shots, but this is not observed for fluctuations between $100-150 \mathrm{kHz}$ (Fig. 6). Similar results are obtained in the $75-95 \mathrm{kHz}$ frequency band. The mode amplitude also does not correlate with the $14 \mathrm{MeV}$ neutron emission (the alpha creation rate) $S_{D T}$ or with ot her plasma parameters $\left(I_{p}, \bar{n}_{e}, B_{T}, W . \tau_{E}, P_{B}\right)$.

Similar results are obtained for the scintillator data. For all three detectors. the normalized signal (loss/neutron) depends weakly on the magnetics amplitude and on $\beta_{p}, S_{D T}, I_{p}, \bar{n}_{e} . n_{e}(0) /\left\langle n_{e}\right\rangle, B_{T} . W, \tau_{E}$, and $P_{B}$.

In retrospect, the null result of this experiment is not surprising.

- In DIII-D, the stability threshold for the beam-driven BAE mode is comparable to the stability threshold for the beam-driven TAE mode [2]. So far. TAE modes driven by alpha particles alone have not been observed in TFTR [29-31] (even in plasmas with $\sim 3$ times larger alpha pressure than in our discharges). In one experiment [32]. the minority ions created by ion cyclotron heating supplemented the instability drive produced by the alpha particles. In this experiment. 
estimates indicate that alpha particles with a central beta of $0.13 \%$ provided $10-30 \%$ of the drive needed to destabilize the TAE mode. If we assume that the alpha drive is proportional to $\beta_{\alpha}$ and make the rough approximation that the damping of the background plasma for the TAE experiment is comparable to the damping of BAE modes in our experiment, the estimated alpha drive in our experiment is only $\sim 15 \%$ of the damping.

- The threshold for beam-driven BAE modes in DIII-D is around $\left\langle\beta_{b}\right\rangle \gtrsim 1 \%$ [4], where $\left\langle\beta_{b}\right\rangle$ is the volume-averaged beam beta. In this experiment. the observed modes in the $50-1.50 \mathrm{kHz}$ are probably destabilized by the beam ions or by the plasma pressure. The beam beta in this experiment is $O(1 \%)$, which is an order of magnitude larger than the alpha beta (Fig. 2c). Thus, in order to make a significant contribution to the instability drive. the alpha particles would have to resonate much more strongly with the BAE modes than the beam ions do.

- Previously, alpha particle losses were correlated with $100-200 \mathrm{kHz}$ MHD activity in a high-current (2.1 MA) supershot plasma [33]. A theoretical analysis [3.3] suggests the modes are kinetic ballooning modes that are destabilized primarily by the background plasma pressure. with the alpha particles with $3_{\alpha}(0) \simeq 0.23 \%$ only making a small destabilizing contribution. Assuming that the general features of this analysis apply to our low-current supershots. the $\lesssim 0.1 \%$ alpha beta in our experiment is too small to excite kinetic ballooning modes.

In summary. any contribution of alpha particles to the destabilization of BAE or kinetic ballooning modes in low-nrent TFTR supershots is below the threshold of detection. Is a romgh istimate. the alpha-particle drive appears to be an order of magnitnde wraker than the drive associated with the background plasma and beam ions. These data should be useful in testing the emerging theories of the B.1K: mode.

The many contributions of H hr IITR : ram are gratefully acknowledged. particularly helpful suggestions by R. Budny: H. Duong, R. Hawryluk. D. Mikkelsen. D. Mueller. K. Owens. and I. St rachan. This work was supported by the U. S. Department of Finror. 


\section{References}

[1] HEIDBRINK, W. W., STRAIT, E. J., DOYLE, E., SAGER, G., and SNIDER, R. T., Nucl. Fusion 31 (1991) 1635.

[2] HEIDBRINK, W. W., STRAIT, E. J., CHU, M. S., and TURNBULL, M. S., Phys. Rev. Lett. 71 (1993) 855.

[3] CHU, M. S., GREENE, J. M., LAO, L. L., TURNBULL, A. D., and CHANCE, M. S., Phys. Fluids B 4 (1992) 3713.

[4] HEIDBRINK, W. W., CAROLIPIO, E. M., JAMES, R. A., and STRAIT, E. J., Nucl. Fusion 35 (1995) 1481.

[5] NAZIKIAN, R., CHANG, Z., FREDRICKSON, E. D., et al., Phys. Plasma 3 (1996) 593.

[6] TSAI. S.-T. and CHEN, L., Phys. Fluids B 5 (1993) 3284.

[7] BRIGUGLIO, S., KAR, C., ROMANELLI, F., VLAD, G., and ZONCA, F., Plasma Phys. Controlled Fusion 37 (1995) A279.

[8] CHENG. C. Z., GORELENKOV, N. N., and HSU, C. T., Nucl. Fusion 35 (1995) 1639.

[9] SANTORO, R. A. and CHEN, L., Phys. Plasma 3 (1996) in press.

[10] STRACHAN, J. D., Nucl. Fusion 34 (1994) 1017.

[11] BUDNY, R. V., BELL. M. G.. JANOS, A. C., et al., Nucl. Fusion 35 (1995) 1497.

[12] BUDNY, R. V., Nucl. Fusion 34 (1994) 1247.

[13] PARK, H. K., Rev. Sci. Instrum. 61 (1990) 2879.

[14] JANOS, A., MCCARTHY. II., FREDRICKSON. E., MCGUIRE. K.. and TAYLOR, G.. Rev. Sci. Instrum. 66 (1995) 668.

[15] STAUfFER, F. J., BOYD. D. A.. CUTLER, R. C., et al., Rev. Sci. Instrum. 56 (1985) 925.

[16] SYNAKOWSKI, E. J.. BELL. R. E.. and BUSH, C. E., Rer. Sci. Instrum. 66 (1995) 649. 
[17] STRAIT, E. J., HEIDBRINK. W. W., and TURNBULL, A. D., Plasma Phys. Controlled Fusion 36 (1994) 1211.

[18] LAO. L. L., ST. JOHN. H., STAMBAUGH, R. D., KELLMAN, A. G., and PFEIFFER, W. P.. Nucl. Fusion 25 (1985) 1611.

[19] LEVINTON, F. M.. Rev. Sci. Instrum. 63 (1992) 5157.

[20] FREDRICKSON, E.. MCGUIRE. K. M., and CHANG, Z. Y., Rev. Sci. Instrum. 66 (1995) 813.

[21] CHANG. Z., FREDRICKSON. E. D.. CALLEN, J. D., et al., Nucl. Fusion 34 (1994) 1309.

[22] ChANG, Z.. CALLEN. J. D., FREDRICKSON, E. D., et al., Phys. Rev. Lett. 74 (1995) 4663.

[23] CHANG, Z., FREDRICKSON, E. D., ZWEBEN. S. J., et al., Nucl. Fusion 35 (1.995) 1469.

[24] TURNBULL. A. D.. CHU. M. S.. STRAIT, E. J., et al., Phys. Fluids B 5 (1993) 2546.

[25] DARROW. D. S.. HERRMANN. H. W.. JOHNSON, D. W., et al., Rev. Sci. Instrum. 66 (1995) +4 6 .

[26] ZWEBEN. S. J.. DARROW. D. S.. IIERRMANN, H. W., et al., Nucl. Fusion 35 (1995) 893.

[2T] NAZIKIAN. R. and MAZZTC'.ITO. E.. Rev. Sci. Instrum. 66 (1995) 392.

[28] PALí. S. F. and FON(K. R. J.. Rev. Sci. Instrum. 61 (1990) 3496.

[29] FU. G. Y.. CHENG. (.. Z.. BIDNY. R.. FREDRICKSON. E.. and ZWEBEN. S.. Physs. Rer. Letl. 75 (1995) 2336.

[30] BATHA. S. H. LEVINTOX. F. M...SPONG. D. A.. et al., Nucl. Fusion 35 (1995) 1463.

[31] ZWEBEN. S. J.. BCD.T'. R. I.. ('HE.NG. C. Z.. et al., Nucl. Fusion $36(1996)$ in press.

[32] WONG. K. L.. SCIIIIIDT. (... B.ITH... S. H.. et al.. Phys. Rev. Lett. 76 (1996) in press. 
[33] ChANG, Z., BUDNY, R. V., CHEN, L., et al., Phys. Rev. Lett. 76 (1996) 1071. 


\section{Figure Captions}

Figure 1. Comparison between a low-current supershot (discharge \#85863) and a high-current supershot (\#i6iT0). Plasma current $I_{p}$, injected beam power $P_{B}, 14 \mathrm{MeV}$ neutron emission $S_{D T}$. poloidal beta $\beta_{p}$ (from magnetics) and central alpha beta (computed by TRANSP [12]).

Figure 2. (a) Profiles of the electron (solid), thermal deuterium (dot), thermal tritium (chain dot), deuterium beam (solid), and tritium beam (dash) densities in discharge \#85863 at $3.9 \mathrm{~s}$. (The electron profile has been divided by 4.) The abscissa is the square root of the normalized toroidal flux $(\simeq r / a)$. Equal numbers of tritium and deuterium beams were injected; half the beams were co-injected with the current and half were cointerinjected. The electron density is measured by a ten-channel interferometer [13]; the other profiles are computed by TRANSP. (b) Profiles of the electron temperature (dash) as inferred from the electron cyclotron emission [14.15] and of the ion temperature (solid) measured by charge-exchange recombination spectroscopy [16]. (c) TRANSP profiles of the total beta (solid), beam beta (dash), and alpha particle beta (chain dot). Toroidal field on axis $B_{T}(0)=4.2 \mathrm{~T} ; \beta_{T}=0.60 ; \beta_{p}=2.4$.

Figure 3. Comparison of an observed $n=3$ mode at $3.9 \mathrm{~s}$ in discharge \#85863 (dashed line) with several quantities of theoretical interest. The laboratory frequency (measured by magnetic probes) is corrected for the Doppler shift [17] to give the mode frequency in the plasma frame. The shaded regions are the continuum of ideal MLHD as computed by the C.ONT [3] code; the BAE and TAE "gaps" fall below and between the continuum bands, respectively. The solid lines within the shaded region represent the continuum for $n=3$ modes. The solid horizontal lines in the BAE gap represent "BAE" modes found by the ideal MIHD code GATO [24]; the length of the line represents the approximate spatial extent of the mode. The dotted line labeled " $\mathrm{KBM}$ " is the expected frequency of an $n=3$ kinetic ballooning mode with frequency $\omega_{-2, p} / 2 \pi$. The equilibrium is computed by EFIT [18] using magnetics data. motional Stark effect (MSE) [19] measurements and kinetic profiles from TR.MSP: the EFIT $q$ profile is also shown. The Doppler shift correction uses toroidal rotation and temperature profiles measured by charge exchange recombination spectroscopy [16] and the mass density and KBM profiles are obtained from TRANSP (Fig. 2). The abscissa is the normalized poloidal llux.

Figure 4 . Average $\dot{B}$ amplitude of magnetic activity from a toroidal array of magnetic probes on shot \#.5963 at $3.76 \mathrm{~s}$. The toroidal mode 
numbers inferred [20] from the relative phase of the probe data are given.

Figure 5. Time evolution of $\beta_{p}$, bandpass-filtered magnetics signal, and the normalized fusion product losses in the DT shot \#85863 and in a comparison DD discharge (\#85864). The fusion-product detector [25] measures alpha particles in the DT discharge (the signal is normalized to the DT neutron emission). In the DD discharge, alpha particles produce $\sim 65 \%$ of the signal and tritons and protons produce the remaining $\sim 35 \%$. (Since the DD fusion products produce $2 / 3$ of the light produced by alpha particles [25], the signal is normalized to $S_{D T}+\frac{2}{3} S_{D D}$.) The detector is at the bottom of the machine $\left(90^{\circ}\right)$.

Figure 6. Bandpass magnetics amplitude versus $\beta_{p}$ for DT (circle) and DD (square) discharges. 

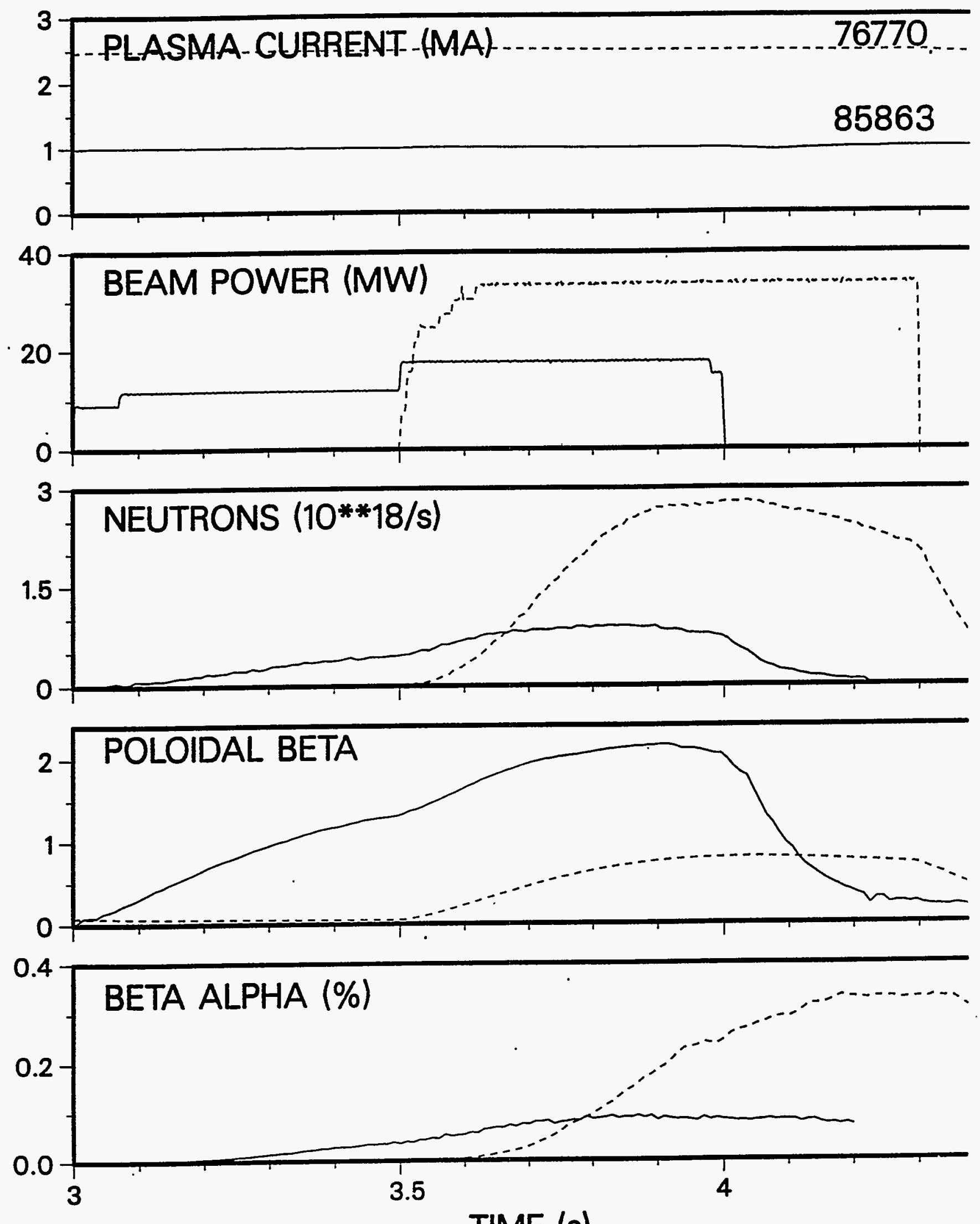

TIME (s) 

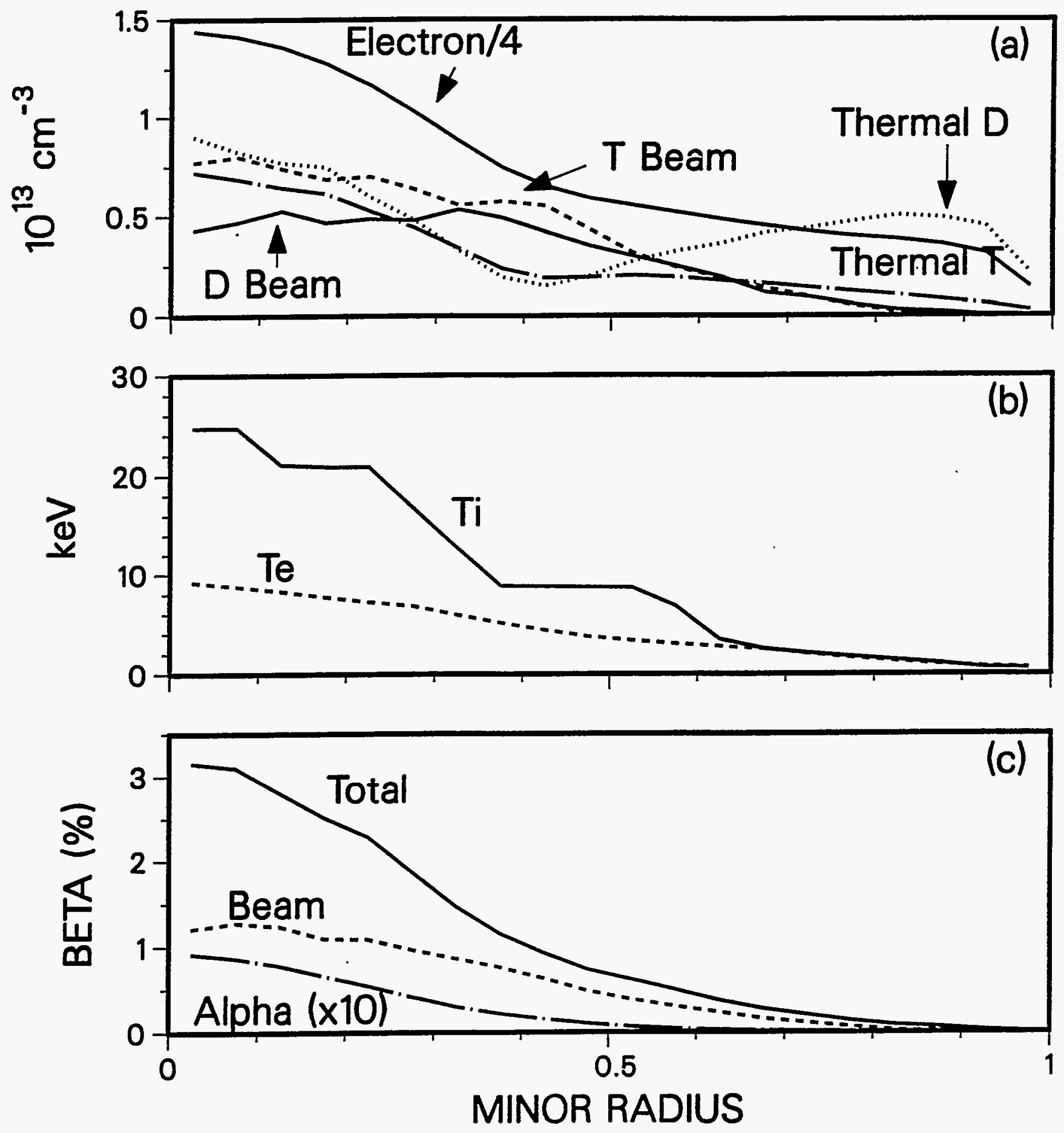

Fig. 2 

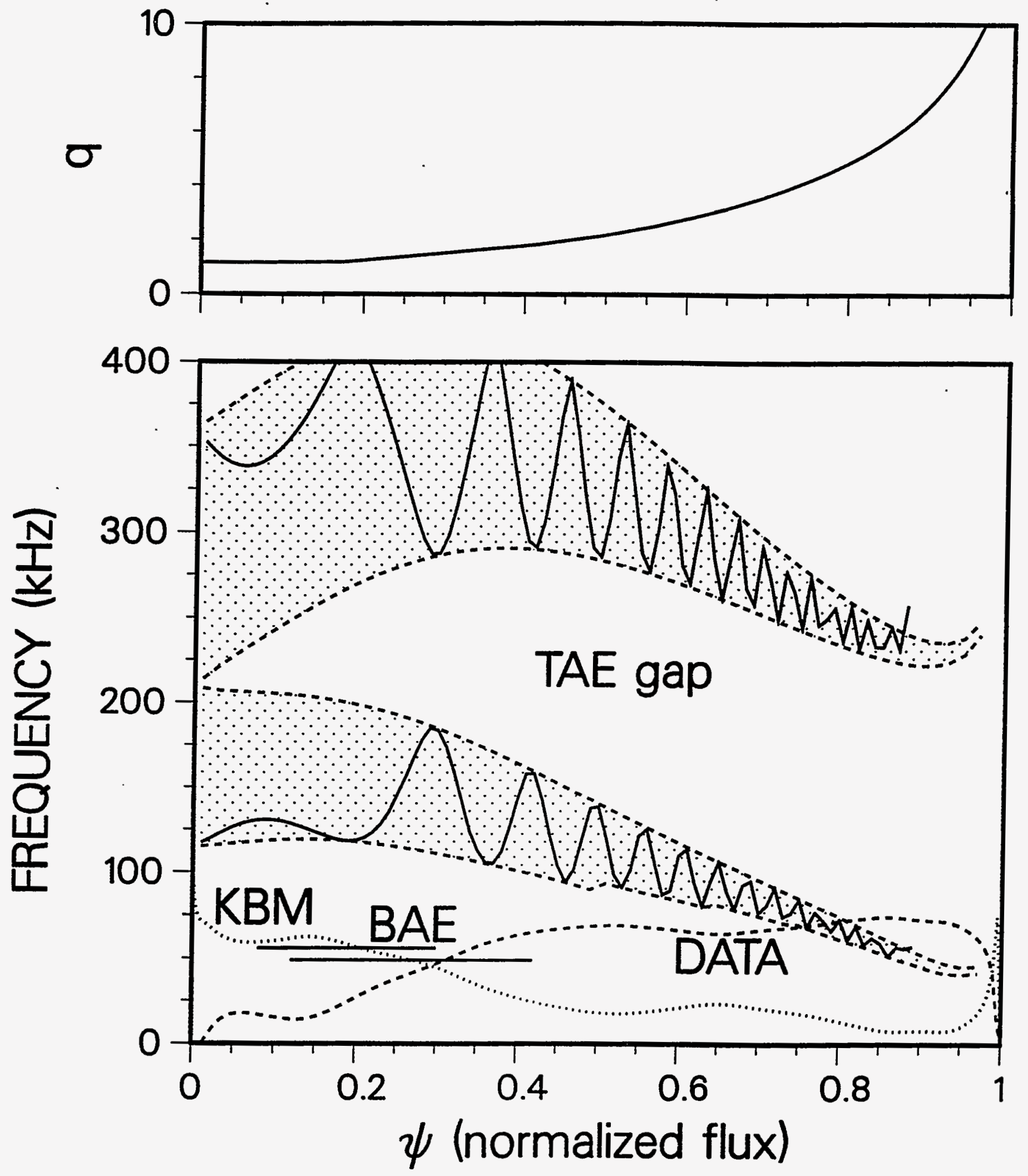

Fig. 3 


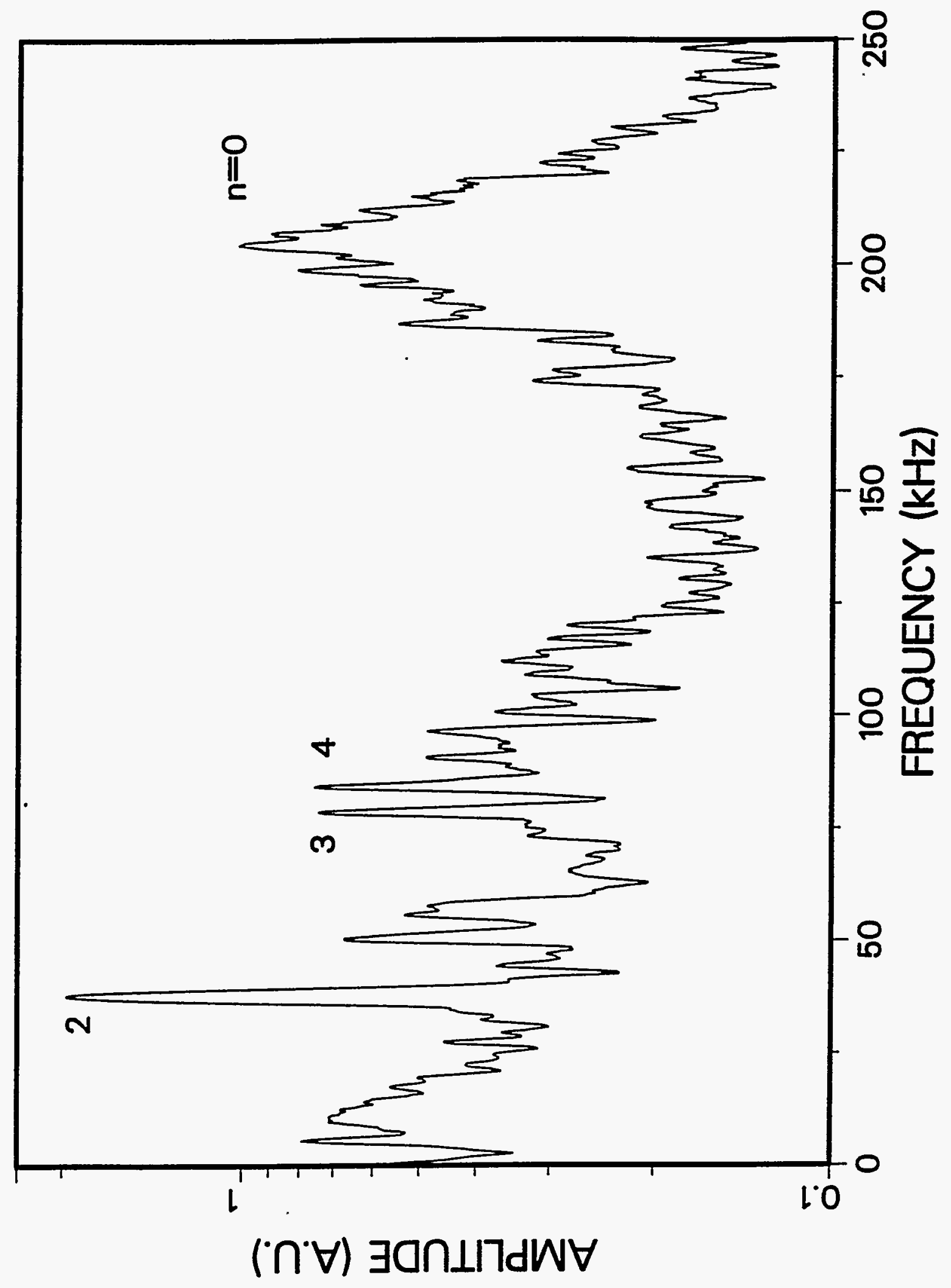

Fig. 4 


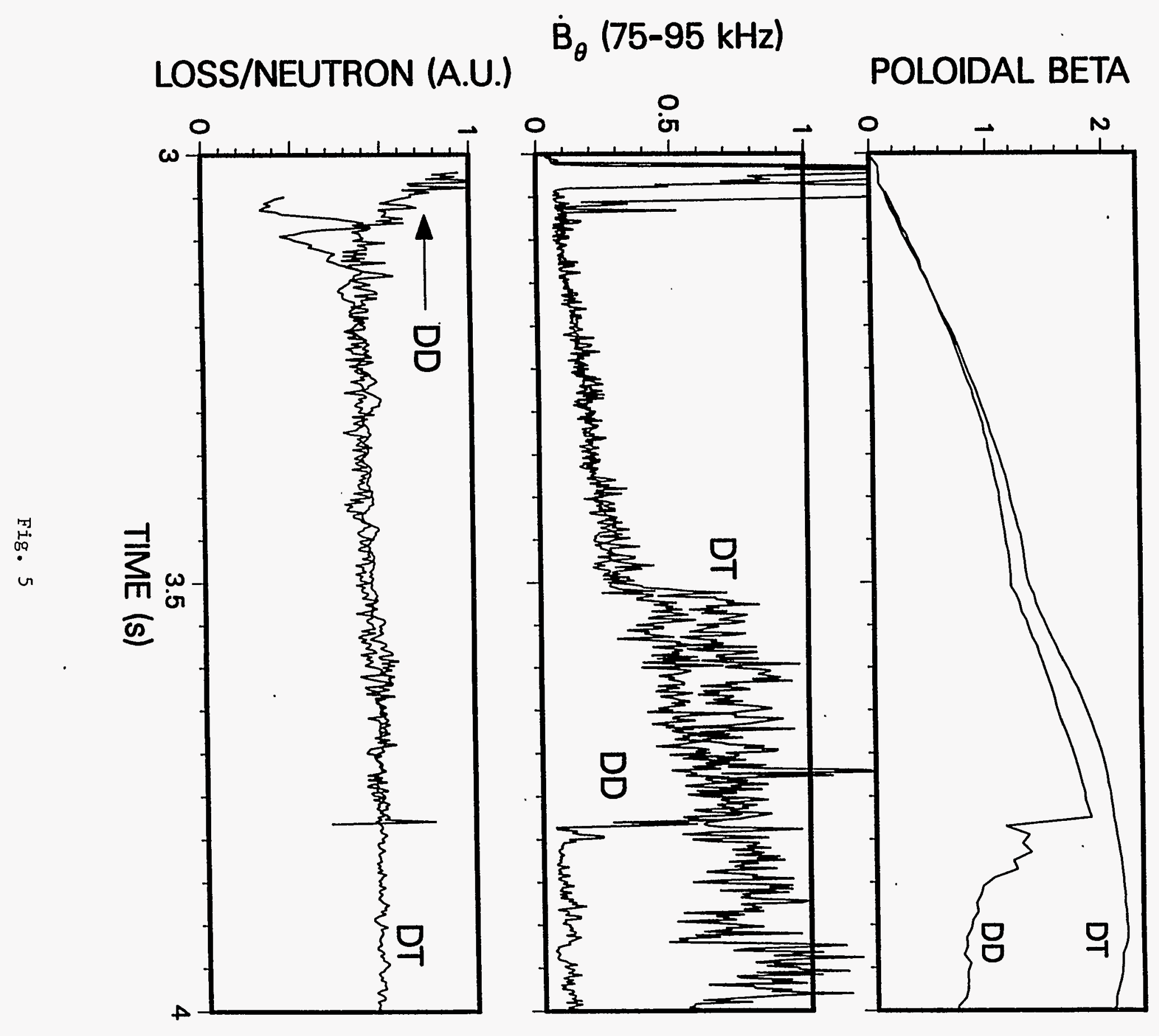




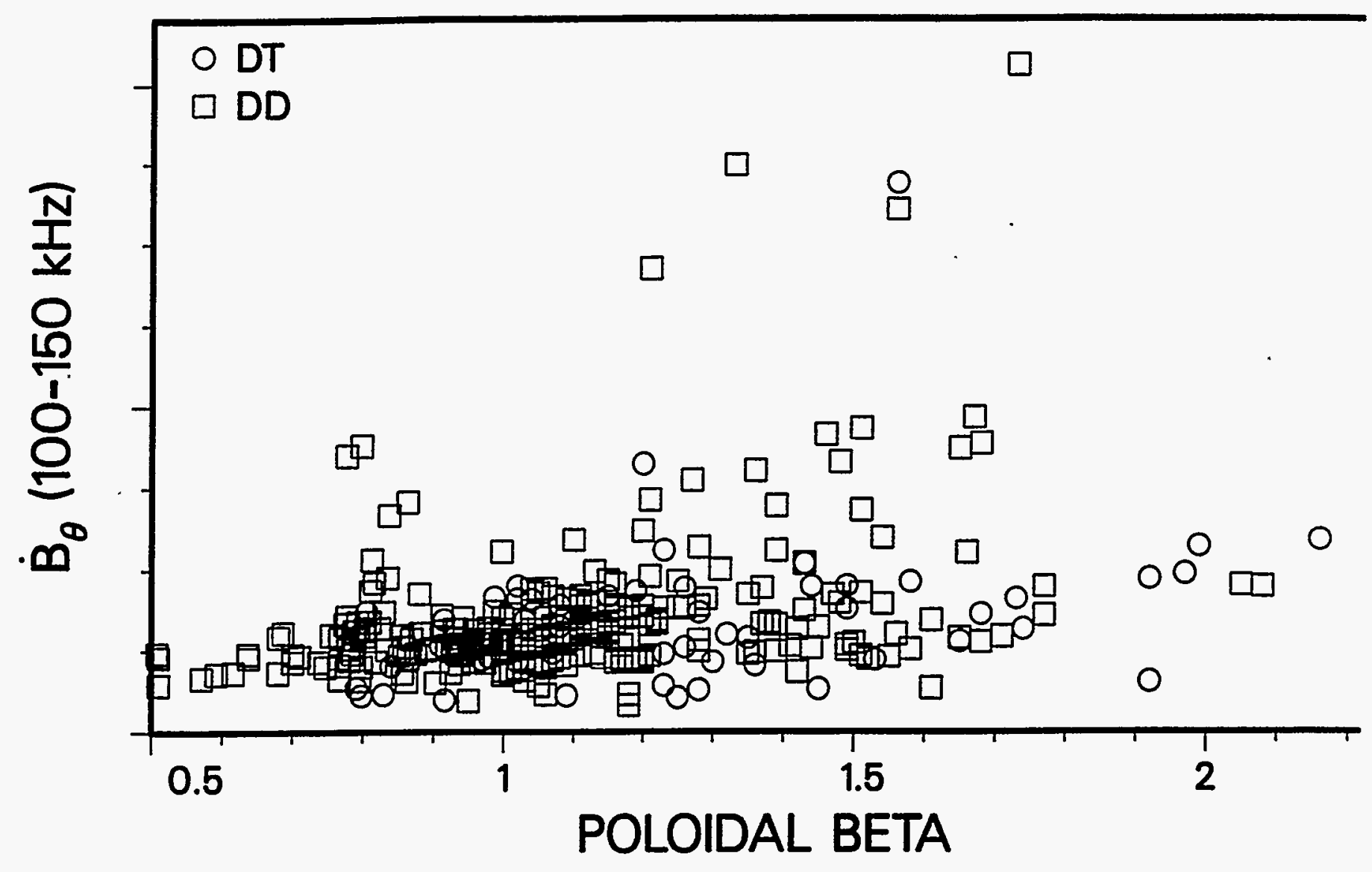

Fig. 6 
